\title{
Necessity is the mother of invention: Alternative techniques in living-related lobar transplantation come to the mainstream
}

Dustin M. Walters, MD, and Alexander Sasha Krupnick, MD

\author{
From the University of Virginia Lung Transplant Program, Department of Surgery, University of Virginia, Char- \\ lottesville, Va. \\ Disclosures: Authors have nothing to disclose with regard to commercial support. \\ Received for publication Nov 2, 2016; accepted for publication Nov 2, 2016; available ahead of print Dec 7, 2016 \\ Address for reprints: Alexander Sasha Krupnick, MD, University of Virginia Lung Transplant Program, Depart- \\ ment of Surgery, University of Virginia, 1215 Lee St, Charlottesville, VA 22908 (E-mail: sashak@ virginia. \\ edu). \\ J Thorac Cardiovasc Surg 2017;153:487 \\ $0022-5223 / \$ 36.00$ \\ Copyright (c) 2016 by The American Association for Thoracic Surgery \\ http://dx.doi.org/10.1016/j.jtcvs.2016.11.014
}

More than 1400 people are currently waiting for lung transplantation in the United States alone. The donor organ shortage is compounded even more in countries such as Japan where, despite the legalization of organ procurement from brain-dead donors in the late 1990s, cultural beliefs still limit cadaveric organ donation. ${ }^{1}$ Some regions of the world, where religious beliefs dominate cultural attitudes, severely limit transplantation options for those with endorgan failure. ${ }^{2}$ To address this need, living-related organ transplantation has become a frequently utilized option in many circumstances.

Since the initial early reports of living-related lobar transplantation, the Starnes and Date ${ }^{3-5}$ groups have led the way in pioneering these innovative techniques. Date and colleagues ${ }^{5}$ report their overall success of expansion in surgical techniques of living-related lobar transplantation. They demonstrate that, in addition to the standard technique of implanting the lower right and left lobes from 2 healthy donors, nontraditional transplant techniques are similarly successful. Specifically, the use of inverted right lobar transplantation in the left chest cavity and the sparing of native upper lobes, as well as right lobar transplantation with concomitant left pneumonectomy, are viable options. The need for postoperative extracorporeal membrane oxygenation support, tracheostomy, or prolonged mechanical ventilation was similar between the 2 groups. Careful preoperative planning, including functional size matching using forced vital capacity and anatomic size matching using 3-dimensional computed tomography, contributed to the postoperative outcomes. This clinical success for recipients is relevant in light of the low complication rates reported for living donors. ${ }^{6}$ The decreased incidence of both acute and chronic rejection after living compared with cadaveric

\section{References}

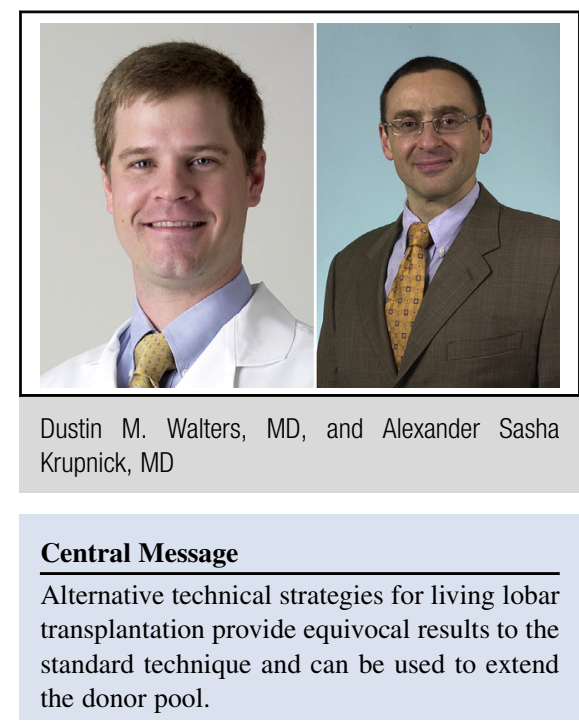

See Article page 479

lung transplantation highlights the utility of organs obtained in the absence of the organ deterioration associated with brain death. ${ }^{7}$ Based on the ever-present organ shortage, the success reported by Date and colleagues ${ }^{5}$ highlights ongoing innovation necessary to meet our patients' needs.

1. Kimura R. Organ transplantation and brain-death in Japan. Cultural, legal and bioethical background. Ann Transplant. 1998;3:55-8.

2. Oliver M, Woywodt A, Ahmed A, Saif I. Organ donation, transplantation and reli gion. Nephrol Dial Transplant. 2011;26:437-44.

3. Starnes VA, Lewiston NJ, Luikart H, Theodore J, Stinson EB, Shumway NE Current trends in lung transplantation. Lobar transplantation and expanded use of single lungs. J Thorac Cardiovasc Surg. 1992;104:1060-5; discussion 1065-6.

4. Shimizu N, Date H, Yamashita M, Aoe M, Nagahiro I, Yoshikawa T, et al. First successful bilateral living-donor lobar lung transplantation in Japan. Nihon Geka Gakkai Zasshi. 1999;100:806-14.

5. Date H, Aoyama A, Hijiya K, Motoyama H, Handa T, Kinoshita H, et al Outcomes of various transplant procedures (single, sparing, inverted) in livingdonor lobar lung transplantation. J Thorac Cardiovasac Surg. 2017;153:479-86.

6. Bowdish ME, Barr ML, Schenkel FA, Woo MS, Bremner RM, Horn MV, et al. A decade of living lobar lung transplantation: perioperative complications after 253 donor lobectomies. Am J Transplant. 2004;4:1283-8.

7. Starnes VA, Woo MS, MacLaughlin EF, Horn MV, Wong PC, Rowland JM, et al Comparison of outcomes between living donor and cadaveric lung transplantation in children. Ann Thorac Surg. 1999;68:2279-83; discussion 2283-4. 